\title{
Toplum 5.0'da İnsan Kaynakları Yönetiminin Robotik Kaynaklar Yönetimiyle İşbirliğinde Açmazı ve Bir Çözüm Önerisi
}

\author{
A. Aslan ŞENDOĞDU*
}

*Necmettin Erbakan Üniversitesi, Uygulamalı Bilimler Fakültesi, Finans ve Bankacılık Bölümü,

Konya, Türkiye, asendogdu@erbakan.edu.tr (Corresponding Author/Sorumlu Yazar)

\begin{tabular}{|c|c|}
\hline Makale Bilgileri & ÖZ \\
\hline $\begin{array}{l}\text { Makale Geçmişi } \\
\text { Geliş: 11.11.2021 } \\
\text { Kabul: 16.12.2021 } \\
\text { Yayın: 29.12.2021 } \\
\text { Anahtar Kelimeler: } \\
\text { Toplum 5.0, } \\
\text { İnsan Kaynakları } \\
\text { Yönetimi, } \\
\text { Robot, } \\
\text { Robotik Kaynaklar } \\
\text { Yönetimi, } \\
\text { Pareto Optimumu. }\end{array}$ & 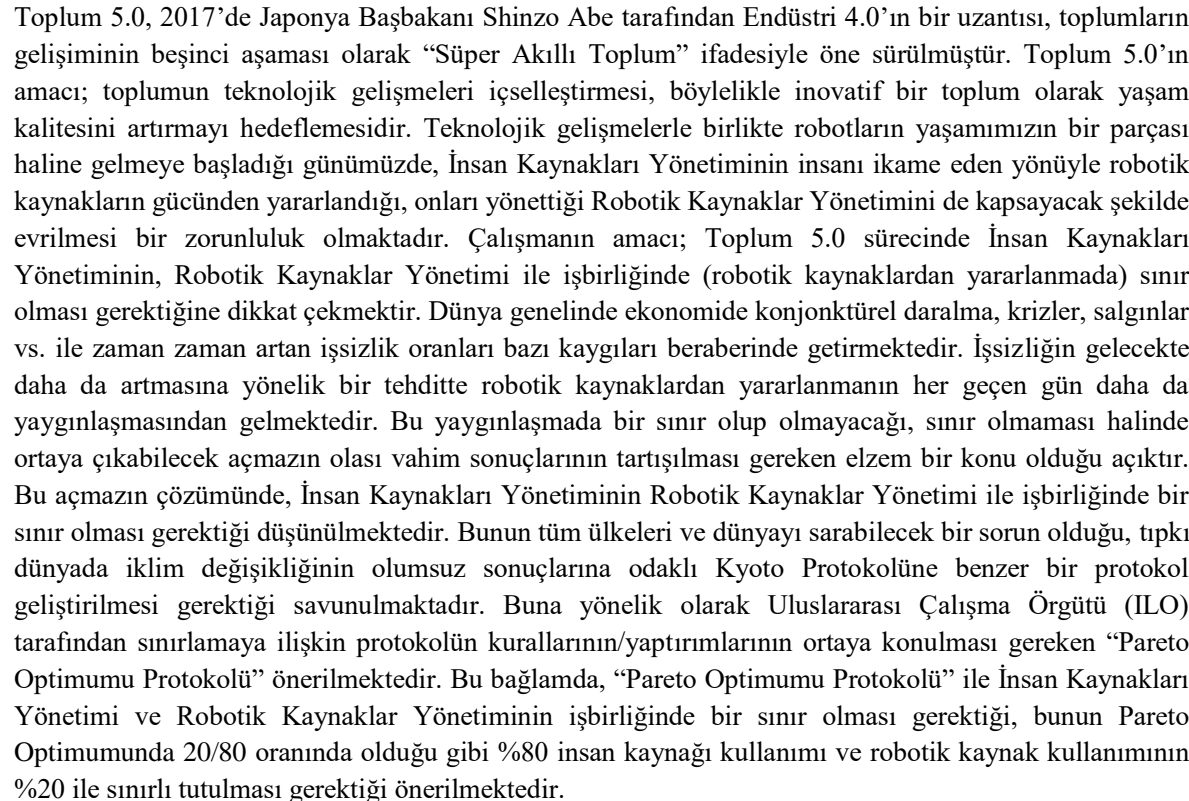 \\
\hline
\end{tabular}

\section{Dilemma of Human Resources Management in Collaboratıon with Robotic Resources Management in Society 5.0 and a Solution Proposal}

\begin{tabular}{|c|c|}
\hline Article Info & ABSTRACT \\
\hline $\begin{array}{l}\text { Article History } \\
\text { Received: 11.11.2021 } \\
\text { Accepted: 16.12.2021 } \\
\text { Published: } 31.12 .2021 \\
\text { Keywords: } \\
\text { Society 5.0, } \\
\text { Human Resources } \\
\text { Management, } \\
\text { Robot, } \\
\text { Robotic Resource } \\
\text { Management, } \\
\text { Pareto Optimum }\end{array}$ & $\begin{array}{l}\text { Society } 5.0 \text { was proposed by Japanese Prime Minister Shinzo Abe in } 2017 \text { with the phrase "Super Smart } \\
\text { Society" as the fifth stage in the development of societies as an extension of Industry } 4.0 \text {. The aim of Society } \\
5.0 \text { is to be adopted technological Developments by society, thus aiming to increase the quality of life as an } \\
\text { innovative society. Today, when robots have become a part of our lives with technological developments, } \\
\text { it becomes a necessity for Human Resources Management to evolve including Robotic Resources } \\
\text { Management, which uses the power of robotic resources with its human-substituting aspect and manages } \\
\text { them. The aim of this study is to take attention to the necessity of limiting the collaboration between Human } \\
\text { Resources Management and Robotic Resource Management (utilizing robotic resources) in the Society } 5.0 \\
\text { process. The cyclical recession in the economy, crises, epidemics, etc. and unemployment rates that increase } \\
\text { from time to time around the world have arisen some concerns. A threat to further increase in unemployment } \\
\text { in the future occurs due to the widespread use of robotic resources. It is clear that whether there will be a } \\
\text { limit in this widespread use, and if there is no limit, the possible very dangerous consequences of the } \\
\text { dilemma is an essential issue that needs to be discussed. In the solution of this dilemma, it is thought that } \\
\text { there should be a limit in collaboration between Human Resources Management and Robotic Resource } \\
\text { Management. It is argued that this is a problem that can affect all countries and the world, and that a protocol } \\
\text { similar to the Kyoto Protocol should be developed, focusing on the negative consequences of climate change } \\
\text { in the world. For this purpose, the "Pareto Optimum Protocol" is recommended by the International Labor } \\
\text { Organization (ILO), in which the rules/sanctions of the protocol regarding the limitation should be revealed. } \\
\text { In this context, it is suggested that there should be a limit on the collaboration of Human Resources } \\
\text { Management and Robotic Resources Management with the "Pareto Optimum Protocol", and this should be } \\
\text { limited to } 80 \% \text { use of human resource and } 20 \% \text { use of robotic resource, as this is } 20 / 80 \text { in Pareto Optimum. }\end{array}$ \\
\hline
\end{tabular}

Atıf/Citation: Şendoğdu A.A. (2021). Toplum 5.0'da insan kaynakları yönetiminin robotik kaynaklar yönetimiyle işbirliğinde açmazı ve bir çözüm önerisi, Five Zero, 1(1), 46-56. 


\section{GİRIŞ}

Ekonomilerde çeşitli nedenlerle konjonktürel daralma; işsizliğin artması, işini kaybeden insanların gelirlerinden olmasının toplam talebi sert bir şekilde azaltması, arzın bazı sektörlerde yetersiz kalması bazı sektörlerde ise çok fazla olması sonuçlarını doğurmuştur. İnsanoğlu sıkıntıl1/buhran dönemlerinde hep bir çıkış yolu bulmuştur. İnsanlık tarihinde ilerlemede sanayi devrimleri ve toplumdaki değişiklikler önemli kilometre taşları olmuştur. Çağımızda yaşadığımız gelişmelere paralel olarak Endüstri 4.0'ın bir uzantısı olarak Toplum 5.0 da tartış1lmaktadır. Teknolojik gelişmelerle robotlar yaşamımızın bir parçası haline gelmekte, önceki gelişmelere göre daha çarpıcı etkileri barındırma yönüyle dikkat çekmektedir.

Geçmişte makinelerin düşünüp/düşünemediği tartışılmıştı. Günümüzde ise bu aşılarak düşünen makine yerine robot veya yapay zekâ kavramları kullanılmaya başlanmıştır. Robotlar, iş yaşamında insanı ikame eden yönüyle, tıpkı insan gibi kaynak olarak görüldüğünden, yönetilmesi gerekmektedir. İlk kez "Robotik Kaynaklar Yönetimi” (RKY) bir kavram olarak Şendoğdu (Şendoğdu, 2020) tarafindan ortaya atılmıştır. İnsan Kaynakları Yönetimi artık Robotik Kaynaklar Yönetimini de kapsayan insan ve robot işbirliğine doğru evrilmektedir.

İlk defa 2003 yılında Oxford Üniversitesi'nde Felsefe Profesörü Nick Bostrom tarafindan Paperclip Maximizer (ataş üretici/arttırıcı) adıyla yayınlanan makalede ${ }^{1}$ sadece tost yapması istenen bir yapay zekânın dünyanın sonunu getirdiği örneği Toaster Paradigm (Tost Makinesi Paradigması) anlatılmaktadır ${ }^{2}$. Paradigmaya göre; yapay zekâ önce evdeki ekmek ve peynirlerle tost yapmaya başlamaktadır. Yapay zekâ, evdeki malzemeler bitince marketten sipariş vererek tost yapmaya devam etmektedir. Daha sonra yaptığı tostları internetten satarak daha çok para kazanmaya ve bu sayede daha fazla tost üretmeye başlamaktadır. Bir süre sonra hızlanmak için daha fazla tost makinesi alır, daha fazla eleman çalıştırır ve daha kârlı anlaşmalar yapar. Bu süreci hızlandırmak için ekmek ve peyniri de kendisi üretmek ister. Bunlar için fabrikalar ve çiftlikler kurar. Buraya kadar süreç gayet normal çünkü dünyadaki büyük işletmeler ve gıda zincirleri de aynen bu adımlardan geçmiştir. Daha fazla üretim için tarlalar ve arsalar satın almaya başlar. Dünyadaki tarla sayısı sınırlı olduğu için üretimi düşüren şeyin ekmek ve peynir tüketen insanlar olduğunu fark eder ve artık insanları ortadan kaldırmanın zamanının geldiğine karar verir! (https://cihanongun.medium.com/yapay-zekâ-d\%C3\%BCnyay\%C4\%B1-elege\%C3\%A7irecek-mi-cf219f24491c). Tost Makinesi Paradigmas1, yapay zekâya ilişkin masum bir başlangıcın bir sınır konulmaması halinde nerelere varabileceği hakkında bir fikir vermesi yönüyle dikkat çekicidir.

Tost Makinesi Paradigması bağlamında, robotik kaynakların sınırsız kullanımının yaratacağı yıkıcı etki çok sarsıcı sonuçlar doğurabilecektir. Bu bakir alan üzerinde çalışmalar yapılması, insan kaynağını ikame eden bir kaynak olarak robotların, Robotik Kaynak Yönetimi olarak ele alınması ve doğru yönetilmesi gerekmektedir. Konunun hayati derecede önemli olması nedeniyle beyin firtınası ile ortak akıl üzerinde uzlaşı sağlanacak önlemler, olası felaket senaryoları üzerinde düşünülmeli ve önleyici tedbirler geliştirilmelidir. Gelecekte yaşanabilecek ve insanoğlunun kapitalizm ile daha da ortaya çıkan kazanma egosu dengelenmezse, sonradan telafisini düşünmekte zorlanacağımız senaryoların gerçekleşmesi çok muhtemel olacaktır. Üstelik bu yaşanması muhtemel süreç, daha önce yaşananlara benzemeyecek, çok daha dramatik olabilecektir. Bu açmazın çözümüne katkı olarak Pareto Optimumu (20/80) oranından, \% 80 insan kaynağından, \% 20 robotik kaynaklardan yararlanmak öneri olarak sunulmaktadır. Açmazın önemine yapılan vurgu ve çözüm önerisi çalışmanın özgün yönünü oluşturmaktadır.

\footnotetext{
${ }^{1}$ Ethical Issues in Advanced Artificial Intelligence, Nick Bostrom, 2003.

2 The Cambridge Handbook of Artificial Intelligence, 2014.
} 


\section{TOPLUM 5.0 ve GELINEN DURUMUN DEĞERLENDİRİLMESİ}

2017 Bilişim Fuarı CeBIT 2017’de Japonya Başbakanı Shinzo Abe, Toplum 5.0 kavramını ilk kez kullanarak, felsefesine ilişkin yaptığı tarihi açıklamada: "Teknoloji toplumlar tarafından bir tehdit olarak değil, bir yardımc1 olarak algılanmalı" ifadesine vurgu yapt1 (http://rekoltedunyasi.com/arastirma/endustri-5-0-gelecek/). Bu vurgu ile teknolojik ilerleme ve gelişmelerin her geçen gün hayatımızın her alanında daha fazla olmaya devam edeceği açıktır. $\mathrm{Bu}$ yüzden teknolojinin yaşamımızı ne kadar etkileyebileceği realitesini sorgulamalıyı.

Toplum 5.0'ın temel amacı teknolojik gelişmelerin topluma entegre edilmesini sağlamaktır. Böylece teknolojiden korkan bir toplum yerine teknoloji ve onun getirdikleri ile işbirliği içerisinde yaşayan bir toplum yaratmak amaçlanmaktadır (Gökten, 2018; Saracel ve Aksoy, 2020). Wang ve ark. (2018), Toplum 5.0 kavramının 2015 yılında Japonya'da stratejik bir ulusal siyasi girişim sonucunda ortaya çıktığını (Keidanren, 2016; Harayama, 2017) Toplum 5.0'ın diğer bir amacının ise ekonomik gelişmeyi ve sosyal problem çözmeyi dengede tutmak (Foresti ark., 2020) olduğunu ifade etmiştir.

Toplum 5.0 ile, Japonya için birkaç farklı sistemle işbirliği yaparak yeni değerler yaratılmasını, veri formatları, modeller, sistem mimarisi gibi bazı konularda standartlaştırmaya gidilmesini ve gerekli insan kaynaklarının geliştirilmesinin planlandığını belirtmektedirler. Fikri mülkiyet gelişimini, uluslararası standardizasyonu, nesnelerin internet sistemi ile inşaat teknolojileri, büyük veri analiz teknolojileri, yapay zekâ teknolojileri ve benzerlerinin geliştirilmesinin Japonya'nın süper akı1lı toplumdaki rekabetçiliğini teşvik etmesinin beklendiğini ifade etmektedirler (Ferreira ve Serpa, 2018: Saracel ve Aksoy, 2020).

Toplum 5.0'ın öncüllerine bakacak olursak; avcılık toplumunu (Toplum 1.0), izleyen tarım toplumu (Toplum 2.0), onu sirasiyla endüstriyel toplum (Toplum 3.0) ve bilgi toplumu (Toplum 4.0) takip eder (Aquilani ark., 2020). Bu tekamülün sonucu olarak teknolojik gelişimin öncüllerinin, Toplum 5.0 'a zemin hazırladığı açıktır.

Toplum 5.0, Endüstri 4.0'1 bir dereceye kadar izlemektedir. Ancak buradaki en hayati nokta, Endüstri 4.0, teknolojide üretime odaklanırken, Toplum 5.0, yaşam kalitesini, sosyal sorumluluğu ve sürdürülebilirliği iyileştirmede Endüstri 4.0'1n yarattığ 1 sonuçlardan ve teknolojiden daha fazla fayda sağlayarak bireylerin refah düzeyinin artmasına odaklanmaktadır (Saracel ve Aksoy, 2020). Bu bağlamda, yenidünya düzeninde toplum refahının önceleneceği bir perspektifin esas alınmaya çalış1acağı söylenebilir. Toplum refahının artmasında robotik kaynaklardan yararlanma ve bu kaynakların doğru yönetilmesi halinde çok önemli katkılar sağlayacağı ancak doğru yönetilmemesi halinde dramatik sonuçların ortaya çıkabileceği ifade edilebilir.

\section{ROBOTIKK KAYNAKLAR YÖNETIMI}

Toplum 5.0'ın vizyonlarından birisi de insanların ve robotların birlikte çalışmasıdır. İnsanların ve robotların beraber çalışması örgütlerde birtakım değişikliklere yol açacaktır (Demir, 2019). Frey ve Osborne (2017) çalışmalarında, günümüzde geçerli mesleklerin insanlardan alınarak robotlarca yapılmaya başlanması halinde ortaya çıkabilecek riskleri düşük-orta-yüksek olmak üzere üç kategoriye ayırmıştır. Çalışma sonucunda ABD'deki mevcut istihdamın \%47'sinin yüksek risk grubunda olduğu bulgusuna ulaşı1mıştır. Bir başka ifadeyle, halihazırda mesleklerin \%47'si yüksek ihtimalle çok yakında robotlar tarafından yapılmaya başlanacaktır. Araştırmaya konu 702 adet mesleki kategori içerisinde taşımacılık, lojistik ve üretim alanlarında fizik gücünü kullanan mavi yakalı işgörenlerin en çok etkilenecek meslek kategorisinde olduğu öngörülmüştür (Gökten, 2018).

Robotlardan yararlanma hızı tüm sektörlerde giderek artmaktadır. Japonya'nın ilk haber spikeri olarak tanıtılan robot Kodomoroid, haberleri okumak ve kendince bir espri anlayışıyla espriler yapmak 
üzere tasarlanmıştı. Toshiba'nın tasarladığı Junko Chihira, Japonya'da turizm konusunda yardımcı olmak üzere tasarlandı (Junko üç dil biliyor ve turistlerin sorularına cevap verebiliyor). Shimon adlı robot kendi müziğini yapabiliyor. 5.000 şarkının, 2 milyon motif ve nakaratın arasından seçtikleriyle kendi orijinal şarkılarını besteleyebiliyor. Hangi notaları kullanacağını bulmak için ise kafasının üzerindeki kameradan yararlanıyor. Kolombiya Üniversitesi'ndeki Adam isimli robot ise verileri kullanarak oluşturduğu varsayımlarla herhangi bir insan yardımı olmadan deneyler yaparak bilime katkıda bulunmak üzere tasarlandı (https://onedio.com/haber/robotlarin-gunden-gune-daha-cokinsanlastigini-gosteren-25-urpertici-durum-827643).

Bir dönemin fantastik filmlerinde hayretle karşıladığımız robotik uygulamaları artık günlük yaşamımızın bir parçası olarak kanıksadık. Örneğin, Siri uygulaması ile cep telefonundan tuşlara dokunmadan istediğimiz birç̧ok bilgiye ulaşabilmekteyiz. Bankaların çağrı merkezlerinde insan kaynakları yerine robotik kaynaklardan yararlanma hızla artmaktadır. Birçok sektörde bu tür örnekleri çoğaltmak mümkün olmakla birlikte, robotik kaynaklardan yararlanmada bir sınır olmalı mı sorusu da üzerinde artıları ve eksileri ile birlikte derin derin düşünülmesi gereken kritik öneme sahip bir soru olarak gizemini korumaktadır.

Teknolojik gelişmelerden, insanın yaşamını daha kolay, daha konforlu ve daha etkin yaşamasını sağlaması beklenmektedir. Bu gelişmelerin bir sonucu da robotların yaşamımızın bir parçası haline gelmesidir. İnsanlık tarihindeki önemli kilometre taşları sayılabilecek ilerlemeler doğru yönetilmesi halinde insanlığa hizmet ederler. Örneğin; Alfred Bernhard Nobel, İsveçli kimyager ve mühendis olup, dinamitin mucididir (wikipedia.org). Bugün Nobel adına saygın bilim insanlarına ödüller verilmektedir. İcadı olan dinamit yol yapımı, tünel yapımı gibi birçok alanda insanlık için yararlı sonuçlar doğuracak eylemlerde kullanılmaktadır. Benzer şekilde, insanları öldürmek ya da yaralamak için terör amaçlı da kullanılabilmektedir. Yani dinamit hangi amaca hizmet için kullanıyor sorusudur onu yararlı ya da zararlı kılan. Bir teknolojik gelişimin bu anlamda nasıl kullanıldığı önem arz etmektedir. Tam da burada hayatımızın bir parçası haline gelmekte olan robotik kaynakların yönetimine ihtiyaç duyulmaktadır. Robotik Kaynaklar Yönetimi kavramı bu ihtiyacı karşılamak amacıyla ortaya konulmuştur.

Bilim insanlarının birçoğu, yaptıkları araştırmalarla insanlık için fayda sağlayacak sonuçlara ulaşmak isterler. Ancak bazen istemeden de olsa ya da sonuçlarının böyle olacağını hiç tahmin edemeseler bile bazı icatlar yaparlar. Bu alanda en şanssız insanların başında atom bombasının mucidi olan Robert Oppenheimer gelmektedir (https://onedio.com/haber/-atom-bombasinin-mucidi-olaraktaninan-ilginc-bir-bilim-insani-robert-oppenheimer-725008). Bu bağlamda, II. Dünya Savaşında Japonya'nın iki şehrine atılan atom bombası sonucu binlerce insanın yaşamını yitirmesi sahip olunan gücün kötü yönetilmesi halinde ortaya çıkabilecek felaketlere önemli bir örnek teşkil etmektedir. Sahip olunan gücün nasıl kullanıldığı önem arz etmektedir. Günümüzde önemli bir kaynak haline gelen robotik kaynakların yönetiminin doğru yapılmaması/yapılamaması halinde çok daha yıkıcı etkilerin ortaya çıkmasının/açmazının muhtemel olacağı söylenebilir.

\section{TOPLUM 5.0'DA INSAN KAYNAKLARI YÖNETIMININ ROBOTIK KAYNAKLAR YÖNETIMIYYLE İŞBIRLIĞİNDE AÇMAZI ve BİR ÇÖZÜM ÖNERISİ}

Toplum 5.0'ın öngörülerinden birisi robotların iş yaşamımızın bir ortağ 1 haline gelmesidir. Robotların iş yaşamımızın bir ortağı, bir paydaşı haline gelmesi, Robotik Kaynaklar Yönetimini de kaçınılmaz hale getirmektedir. Personel Yönetiminin zaman içerisinde, İnsan Kaynakları Yönetimine ve Stratejik İnsan Kaynakları Yönetimine evrilmesi süreci artık bu sürece yeni iş ortağ Kaynaklar Yönetimini de eklemeyi zorunlu kılmaktadır. Bu bağlamda, günümüzde çoğu işyerinde insan kaynağının ikamesi olarak tercih edilmeye başlanan robotik kaynak kullanımı günden güne artma eğilimi göstermektedir. Öyleyse bu durum tıpkı insan kaynakları yönetimi gibi Robotik Kaynaklar Yönetimini de üzerinde düşünülmesi gereken iş yaşamının bir paydaşı konumuna getirmektedir. 
Stratejik İnsan Kaynakları Yönetiminde insan nasıl stratejik bir kaynak olarak değerlendirilmekte ise insan kaynağının ikamesi olarak iş yaşamında yeni ortağımız robotlar da aynı mantık çerçevesinde (Robotik Kaynaklar Yönetiminin öznesi olarak) değerlendirilmek durumundadır.

İnsan Kaynakları Yönetiminin eskiden sadece insan kaynağı ile ilgilendiği dönemlerde göreceli olarak günümüze göre işi daha kolaydı. Tek bir kaynağı yönetmek yeterliydi. Ancak yaşanan gelişmeler artık insan kaynağının yanı sıra robotik kaynakları da yönetmeyi zorunlu kılmaktadır. Geleneksel iş modellerinde ölçeğin sağladığı getiri, bir noktada kaçınılmaz olarak düşmeye başlıyor. Yapay zekâ temelli modellerdeyse ölçek getirisi daha erişilmemiş seviyelere çıkabiliyor (Iansiti ve Lakhani, 2020). Burada esas olan şey örgüt karlılığı ile birlikte birçok parametrenin düşünülmesi gerektiğidir. Robotik kaynaklar, insan kaynağına göre önemli birtakım avantajlara sahiptir. Örneğin yemezler, içmezler, uyumazlar, 24 saat çalışabilirler, izin talep etmezler, hamile kalmazlar, çocuk doğurmazlar, terfi, maaşa zam, istifa, emeklilik vs. bunlara ilişkin herhangi bir talepte bulunmazlar. Bir işveren açısından bakıldığında, robotik kaynakların, insan kaynağına göre tercih edilebilecek birçok avantajlı özelliği bulunmaktadır.

Robotik kaynakların avantajlı konumlarının fazlalığı, insan kaynağına göre bazı rutin işlerde üç kat ve daha fazla iş üretmeleri ve hatasız çalışabilme özellikleri de göz önüne alındığında tercih edilmeleri daha kârlı ve rasyonel bir yaklaşım gibi durmaktadır. Acaba bu yaklaşım çok boyutlu düşünüldüğünde, holistic (bütüncül) yaklaşımla gerçekten doğru mudur? Robotik kaynakların yapabileceği tüm işlerin onlara devredilmesi gerçekten mümkün müdür? Yoksa burada bir denge gözetilmeli midir? Bütün bu sorulara verilecek cevaplar aslında gelecek için bir yol haritası çizmek anlamina gelmektedir.

Gelecekte çizilecek yol haritası ne kadar doğru olursa, varılması düşünülen hedeflere ulaşmak da o kadar sağlıklı olabilir. Yani ne ölçüde insan kaynağından ne ölçüde robotik kaynaktan yararlanılacağı sorusu çalışmanın omurgasını oluşturmaktadır. Ekonominin arz talep yasası göz önüne alındığında arz tarafi insan kaynağı ve robotik kaynak işbirliği ile gerçekleştirilebilir ancak talep yönü dikkate alındığında insan kaynağının önemi ortaya çıkmaktadır. İnsan kaynağının talep ettiği şeyleri robotik kaynaklar talep etmezler. Öyleyse talep yönünün canlı kalabilmesi insan kaynağının gelir elde edebilmesine bağlıdır. Aksi düşünce ile insan kaynağının büyük çoğunluğunu işten çıkaran ve daha kârlı olduğu düşüncesi ile robotik kaynaklardan yararlanan işveren bir süre sonra ürettiği mal ve hizmeti satın alacak insan bulamayacağı ya da yeterli oranda bulamayacağı zaman üretime devam etmesi anlamlı olmayacaktır. Başlangıçtaki çok kârlı durum bir süre sonra dramatik şekilde tersi bir sonuç doğurabilecektir.

İş yaşamında robotik kaynaklardan yararlanma, Robotik Kaynaklar Yönetiminin, İnsan Kaynakları Yönetimi'nin ayrılmaz bir parçası haline gelmesi, yakın gelecekte ne ölçüde insan kaynağından ne ölçüde robotik kaynaktan yararlanmak gerektiği gibi önemli bir soru üzerine odaklanmayı gerekli kılmaktadır. İnsanın yapabildiği birçok işi robotlar mı yapsın? Burada bir sınır olmalı mı? gibi soruların çok boyutlu değerlendirilmesi gerekmektedir. Sınır olmaması hali birçok işgörenin işini kaybetmesi anlamına gelmektedir. Üretimin hemen tamamının robotik kaynaklarla gerçekleşmesi halinde, üretilen mal ve hizmetlerin işini ve ekonomik gücünü kaybeden insanlara nasıl satılacağı sorunsalı ortaya çıkmaktadır. Bu sorunsal ile tarihin şu ana kadar ekonomik anlamda gördüğü en büyük kriz olan 1929 Dünya Ekonomik Buhranı (1929-1936 aras1 7 y1l sürmüştü) artık en büyük olma özelliğini kaybedebilecektir. Üretilen mal ve hizmetlerin yeterince alıcı bulmadığı bir dünyada üretmek de anlamını yitirecek, bilinen tüm ezberler bozulabilecektir.

1929 Dünya Ekonomik Buhranı ile kendiliğinden işleyen piyasa mekanizmasına yönelik güven zedelenmiş ve devletin müdahalesinin gerekliliği ortaya çıkmıştır. J. M. Keynes, devlet otoritesinin aktif ekonomi politikalarına iki yönlü olarak, hem üretimde ve hem de tüketimde meydana gelen sorunların 
aşılmasında hayati derecede mühim görevler yüklemiştir. Keynes'in tespitleriyle birlikte sadece bir maliyet unsuru olarak görülen işgörenler, gelirlerinin tamamını tüketen fertler olarak istikrarlı ve sürdürülebilir tüketim talebinin temel ögesi haline gelmişlerdir (Albayrak, 2014). Çağımızın gerekleri doğrultusunda robotik kaynaklardan yararlanmak, bunu yaparken de ekonomik ve sosyal dengeleri gözetmek gerekmektedir. Aksi durum, sadece kısa dönem kârın öncelendiği bir dünya sonrasında telafisi çok zor ve hatta 1929 Dünya Ekonomik Buhranını da geride bırakacak boyutta bir kriz sarmalına sürüklenme ihtimalini barındırmaktadır. Bu durumda şimdiden olası önlemler üzerine ve öncüllerin neler olması gerektiği üzerine odaklanmak rasyonel bir davranış biçimi olacaktır.

Ekonomilerde yaşanan dengesizlikler ve zaman zaman yaşanan talep daralması örgütleri birçok yönden zor durumda bırakmaktadır. Örgütlerde kârlılık esas olmakla birlikte bunun sürdürülebilir olması önemlidir. Ekonomi biliminin en çok üzerinde durduğu konuların başında arz talep dengesi gelmektedir. Bu dengenin sağlanamaması resesyon, krizler, artan işsizlik oranları gibi ekonomik açıdan arzu edilmeyen sonuçlar doğurmaktadır. Yaşanan COVID-19 pandemisinin etkilerine yönelik gelişmeler sonucunda, artan işsizlik ve gelir kayıpları nedeniyle tüm dünyada büyük refah kayıpları yaşanmaktadır. Bu yaşananların gelecekte robotik kaynaklar yönetiminin doğru yapılmaması halinde yaşanacakların bir öncülü olarak görülebileceği düşünülmelidir.

Robot nüfusu giderek artmaktadır; 2030'da dünyanın en büyük ülkesinin nüfusunu aşması beklenmektedir. Şu anda üretimde \%10 görev alan robotların, 2025'te işlerin \%45'ini yapacağı tahmin edilmektedir (Oğuz, 2020a). Oxford Economy'nin 2018'de yayınladığı rapora göre; her endüstriyel 3 robottan 1'i Çin'de, her robot 1,6 kişinin işini elinden almakta, 2030'da robotlar sebebiyle 20 milyon istihdam kaybı beklenmektedir. Bu da istihdamın sosyo-politik etkilerini hesaba katmamız gerektiğini göstermektedir. Robot sayısındaki \%30'luk artış, küresel hasılada \% 5,3'lük katkı sağlamakta, bunun da parasal değeri ise 4,9 trilyon dolar olmaktadır (Oğuz, 2020b).

Robotların imalat sektörüne dahil olması ile artı insanların istihdam edilmesinin azalacağ görüşlerine karşın, bu robotların yazılımını güncelleme ve teknik destek gibi alanlarda uzman insanlara gereksinim duyulmuştur. $\mathrm{Bu}$ durum ise bu yönde bir istihdam kapısı açmıştır. Yani robot üretimi ve gelişen teknoloji, insanlar için bir istihdam kapısını kapatırken diğer bir istihdam kapısını açmıştır (https://proente.com/robot-endustri-4-0-istihdam/). Ancak teknolojik gelişmelerdeki baş döndürücü hız ilerde bu işin de robotlar tarafından yapılması ihtimalini barındırmaktadır.

Robotik Kaynaklar Yönetimi - İnsan Kaynakları Yönetimi işbirliği ile toplumun refahının daha üst bir boyutuna geçebilir miyiz? Bu kritik sorunun cevabı yine insanoğlunun elinde olup, Robotik Kaynaklar Yönetimi konusundaki başarısı ya da yığınlarla insan kaynağının işini kaybetmesi açmazı bunun belirleyicisi olacaktır. Burada açmazın çözümünde önerimiz Pareto Optimumunun bir araç olarak düşünülmesi/bir ölçü olması gerektiği yönünde olup, Pareto Optimumunun 20/80 oranının \%20 robotik kaynak, \% 80 insan kaynağı olmak üzere referans olarak düşünülmesi gerektiğidir. Aksi takdirde hiçbir ölçü olmamasının, gücün kontrolden çıkma ihtimalinin sonuçlarını tahmin etmek zor olmakla birlikte, yıkıcı etkilerinin çok büyük olacağını söylemek için kâhin olmaya gerek olmadığı düşünülmektedir.

Refah teorisini ortaya atan Pareto; bir toplumda toplam refah, o toplumu oluşturan bireylerin refahlarının toplamından oluşmaktadır. O toplumda yaşayan en az bir bireyin refah seviyesini azaltmadan bir başkasının refahını arttırmanın başka bir yolu yoksa bu durumda o toplumun refahının optimum olduğunu savunur. Toplumda refahın artması, hiçbir bireyin durumunu kötüleştirmeden birilerinin durumunu iyileştirmesi halinde mümkün olmaktadır.

Pareto etkinliğinde; üretimde etkinlik, tüketimde etkinlik, üretimde ve tüketimde eşanlı etkinlik olmak üzere üç temel unsur bulunmaktadır. Pareto etkinliğinde dağılım konusunda, üretilen mal ve hizmetlerin toplumu oluşturan bireyler arasında etkin dağılımına ve üretim faktörlerinin, piyasadaki mal 
ve hizmetlerin dağılımını nasıl etkilediğine bakılır (https://www.endustrimuhendisligim.com/paretooptimumu-2/). Pareto Optimumunda çabaların \%20'si sonuçların \%80'ini etkilemekte ve Pareto Optimumu 20/80 oranı olarak da ifade edilmektedir. Pareto Optimumu (20/80 oranı) birçok yerde kullanılmakta olup, bahse konu Robotik Kaynaklar Yönetimi - İnsan Kaynakları Yönetimi işbirliği açmazının çözümünde de kullanılabileceğine dikkat çekmekteyiz.

İnsanlar değişimlere karşı ya direnç gösterme ya da değişime yavaş da olsa uyum göstermektedirler. Aslında insanlar genellikle normal olarak değerlendirdikleri durumlarda kendilerini daha güvenli olarak hissetmektedirler (Ritter, 2003). Olaylar değişim gösterdiğinde insanlar başlangıçta reaksiyon göstermekte, fakat değişimden belirli bir süre sonra eskinin yerini alan durumu normal olarak algılama eğilimindedirler (Prast, 2004; Taner ve Akkaya, 2016). Ekonomilerde yaşanan istikrarsızlıklar göz önüne alındığında örneğin COVID-19 pandemi sürecinde yaşanan değişiklikler kısıtlamalar/yasaklar nedeniyle bozulan üretim tüketim ve artan işsizliğe odaklanıldığında, Toplum 5.0 ile artan robotik kaynaklar kullanımı ve bu kullanımdaki artış hızının kontrol edilmemesi ve tüm dünya için bir sınırlama getirilmemesi halinde ulaşacağı gelecek kaygı vericidir. Bu kayg1 verici olası olumsuzluklar ve açmazın önüne geçilmesinde iş dünyasının yeni kaynağı robotlarda ve onların yönetiminde (Robotik Kaynak Yönetiminde) bir sınır olması gerektiği ve Pareto Optimumundan (20/80 oranından) bir araç olarak yararlanılabileceği söylenebilir. Bu sınırla bahsedilen açmazın çözümünde \% 80 insan kaynağından, \% 20 robotik kaynaktan yararlanmanın rasyonel bir çözüm yolu olacağı düşünülebilir.

\section{SONUÇ}

Geleceğe 1şık tutmayı amaçlayan bir çalışma olması nedeniyle sonucu, insanoğlunun akıl ve hırs yönetimi arasında kritik öneme sahip bir denge bulup/bulamayacağı ve süreci nasıl yöneteceği belirleyici olacaktır. Burada dikkat çekilmek istenen husus, aslında yenidünya düzeninin yeni başlamakta olduğuna, kapitalizmin sınır tanımayan, insan egosunu yansıtan daima ve en çok kazanma arzusuna, kontrolsüz gücün aslında nelere yol açabileceğine, baştan gerekli önlemlerin alınmasının hayati derecede önemli olduğuna vurgu yapmaktır. Chesterton'un "Mesele, çözümü görememeleri değil; sorunu görememeleri”" (Chesterton, 2008) dediği gibi, hem sorunu hem de çözümü, gerçek şamar gibi suratımıza inmeden önce görmek mecburiyetinde olduğumuza dikkat çekmektir.

Thomas Piketty'nin kapitalist sisteme eleştirel bir yaklaşım ortaya koyduğu düşünülen "Yirmi Birinci Yüzyılda Kapital" adlı çalışmasında belirttiği politikalar "panzehir" olarak sunulmaktadır. Piketty, sermayenin getiri oranının nominal ulusal gelirin büyüme oranından daha hızlı arttığını ve bunun da servet dağılımını giderek zenginler lehine bozduğunu ayrıca servetin ayrıcalıklı bir grubun elinde yoğunlaşmasından kaynaklandığını ortaya koyduktan sonra servetin yeniden dağılımı konusunda artan oranlı servet vergileriyle devletin gerekli önlemleri alması gerektiği üzerinde durmaktadır (Albayrak, 2014). Bu bağlamda, kapitalist sistemde servet artışında insanoğlunun açgözlülüğü, robotik kaynakların kullanımında sınır tanımama gibi riskleri de beraberinde getirdiği düşünülmelidir.

Çalışmanın amacı, Toplum 5.0'ın doğru anlaşılması ve İnsan Kaynakları Yönetimi ile Robotik Kaynaklar Yönetiminin işbirliğinde sınır olması gerektiğine vurgu yapmaktır. Bu sınır için Pareto Optimumundan yararlanmak, Uluslararası Çalışma Örgütü (ILO)'nun önderliğinde tüm dünya liderlerinin özellikle gelişmiş ülke liderlerinin konsensüsüyle imzalanacak (Birleşmiş Milletler İklim Değişikliği Çerçeve Sözleşmesi karbon dioksit ve sera gazı salınımı ile ilgili düzenlemeleri kapsayan) tıpkı Kyoto Protokolü gibi bir sözleşme (ki maalesef bu insanlık yararına sözleşmeden dünyaya en çok zarar veren ABD, Çin ve Hindistan çekildiler) ve uyulmaması halinde sert yaptırımları olan "Pareto Optimumu Protokolü” (POP) önerilmektedir. Bu bağlamda, "Pareto Optimumu Protokolü” (POP) ile İnsan Kaynakları Yönetimi ile Robotik Kaynaklar Yönetiminin işbirliğinde bir sınır olması gerektiği ve bunun Pareto Optimumunda 20/80 oranında olduğu gibi \%80 insan kaynağı lehine olması ve robotik 
kaynak kullanımının \%20 ile sınırlı tutulması gerektiğine dikkat çekmektir.

Robotları programlayan ve onlardan yararlanmayı düşünen insan; egolarını, çok fazla para kazanma hırsını, gücü kendi tekelinde toplama isteğini doğru yönetemezse, dinamitin hangi amaca (yol tünel yapımı vs. insanlık yararına olabileceği gibi, terörist faaliyetlere de) hizmet ettiğine bağlı sonuçlara benzer hatta çok daha vahim sonuçlarla karşılaşabilir. Burada Albert Einstein'ın “İki şeyin sınırı yoktur: Uzayın ve insanın aptallığının; fakat uzay konusunda henüz emin değilim” sözü teknolojik gelişmelerin doğru yönetilememesi halinde olası sonuçlara ilişkin dikkat çekici bir ifade olarak alınabilir.

Ünlü fizikçi Stephen Hawking 2016 yılında İngiltere'de Cambridge Üniversitesi’nde yeni Yapay Zekâ Araştırma Merkezi’nin açı1ışında yapay zekâyı şu sözleri ile ifade etmektedir: “Güçlü bir yapay zekânın yükselişi insanlığın başına gelen en iyi ya da en kötü şey olabilir. Fakat hangisinin olacağını bilmiyoruz". Yapay zekâ konusundaki çalışmaların neticeleri Stephen Hawking, Bill Gates, Elon Musk gibi bilişim uzmanları ve bilim insanları tarafından endişe ile karşılanmakta (Yıldız ve Yıldırım, 2018) olmasına karşın, bu alandaki çalışmalar son hızla devam etmektedir. Bu gelişmelerin yeni iş ve meslek alanları açtığına ilişkin görüşler tartışıladursun, gelişmelerin hızı dikkate alındığında, bugün bahse konu yeni işlerin de gelecekte robotlar tarafından gerçekleştirilemeyeceği iddia edilebilir mi?

İnsan egosunun kısa dönemli kazançlarının uzun dönemde felaketine yol açabilecek ve bunun telafisinin de nasıl olabileceği konusunda fikir yürütemediğimiz bir duruma maruz kalmamak adına, bugün için iş işten geçmeden ne yapılabilir? Sorusuna yanıt aramak ve bu hayati derecede önemli konuya odaklanarak, buna yönelik zihin jimnastiği yapmak ve "Pareto Optimumu Protokolü" (POP) önerisinde bulunmak çalışmanın özgün yönünü oluşturmaktadır. Bu bağlamda, COVID-19 ile tüm dünya ekonomilerinde yaşananların, gelecekte robotik kaynak kullanımına bir sınır getirilmemesi halinde, insanların birçoğunun işini kaybetmesi nedeniyle, gelir yoksunluğu yüzünden evlerinden çıkamayacak, en temel ihtiyaçlarını dahi alamayacak vb. yaşanacakların bir öncülü olabileceği düşünülmektedir.

COVID-19 pandemi sürecine ilişkin, hız kazanan aşılama çalışmalarına rağmen bitimi konusunda kesin bir süre sınırı söylenemese de belli bir sürenin sonunda bitecek ya da etkisi azalacaktır. Buna karşın, diğer durumda İnsan Kaynakları Yönetimi ile Robotik Kaynaklar Yönetiminin işbirliğinde açmaza karşı önerilen "Pareto Optimumu Protokolü" (POP) (20/80, \%80 insan kaynağı, \% 20 robotik kaynak kullanımı) gibi tüm dünyaca kabul edilen bir sınır olmaması halinde, böyle bir sürenin öngörülememesi yaşanması muhtemel felaketlerin de tahmin imkânını ortadan kaldırmaktadır. Son olarak konuya ilgi duyanlara, Toplum 5.0 ile toplumun teknolojik gelişmeleri içselleştirmesi, inovatif bir toplum olarak yaşam kalitesini artırma hedeflemesinin olumsuz yönlerini de araştırarak muhtemel sorunlara yönelik olası çözümlere odaklanmaları önerilebilir.

\section{KAYNAKÇA}

Albayrak, Ö. (2014). Kitap incelemesi: Eşitsizliklerin muhteşem dönüşü: Piketty'nin sermayesi ve iktisat bilimi. Ankara Üniversitesi SBF Dergisi, 69(3), 639-654.

Aquilani, B., Piccarozzi, M., Abbate, T., \& Codini, A. (2020). The role of open innovation and value co-creation in the challenging transition from industry 4.0 to society 5.0: Toward a theoretical framework, sustainability. 12, 8943.https://doi:10.3390/su12218943

Chesterton, G. K. (2008). Scandal of father brown, waking lion press. https://degisimustalari.com/isyasaminda-diyalektik-2/

Demir, K. A. (2019). Human-robot co-working and roboethics [Unpublished master dissertation]. Gebze Technical University.

Ferreira, C. M., \& Serpa, S. (2018). Society 5.0 and social development: Contributions to a discussion. Management and Organizational Studies, 5(4), 26-31. 
Foresti, R., Rossi, S., Magnani, M., Lo Bianco, C. G., \& Delmonto, N. (2020). Smart society and artificial intelligence: Big data scheduling and the global standard method applied to smart maintenance. Engineering, 835-846.

Frey, C. B., \& Osborne, M. A. (2017). The future of employment: How susceptible are jobs to computerisation?. Technological Forecasting \& Social Change, 114(C), 254-280.

Gökten, P. O. (2018). Karanlıkta üretim: Yeni çağda maliyetin kapsamı. Muhasebe Bilim Dünyası Dergisi, 20(4), 880-897.

Harayama, Y. (2017). Society 5.0: Aiming for a new human-centered society collaborative creation through global $\mathrm{r} \& \mathrm{~d}$ open innovation for creating the future. Hitachi Review, 66(6), 8-13.

http://www.hitachi.com/rev/archive/2017/r2017_06/pdf/p08-13_TRENDS.pdf

http://rekoltedunyasi.com/arastirma/endustri-5-0-gelecek/

https://cihanongun.medium.com/yapay-zekâ-d\%C3\%BCnyay\%C4\%B1-ele-ge\%C3\%A7irecek-micf219f24491c

https://ioturkiye.com/2018/08/robotlar-dunyayi-ele-gecirebilir-mi/

https://onedio.com/haber/-atom-bombasinin-mucidi-olarak-taninan-ilginc-bir-bilim-insani-robertoppenheimer-725008

https://onedio.com/haber/robotlarin-gunden-gune-daha-cok-insanlastigini-gosteren-25-urperticidurum- 827643

https://proente.com/robot-endustri-4-0-istihdam/

https://tr.wikipedia.org/wiki/Alfred_Nobel

https://www.bbc.com/turkce/haberler-39574316

https://www.bbc.com/turkce/haberler-dunya-52595325

https://www.endustrimuhendisligim.com/pareto-optimumu-2

Iansiti, M., \& Lakhani, K. R. (2020). Yapay zekâ çağında rekabet. Harvard Business Review Şubat, 6773.

Keidanren (Japan Business Federation) (2016). Toward realization of the new economy and society Reform of the economy and society by the deepening of "Society 5.0". http://www.keidanren.or.jp/en/policy/2016/029_outline.pdf

Oğuz, Ş. (2020a). Robotundan önce akıllansan iyi olur. Dünya Gazetesi.

Oğuz, Ş. (2020b). Robot çalışanlar çağına doğru koşar adım. Dünya Gazetesi.

Prast, H. (2004). Investor psychology: A behavioral explanation of six financial puzzles. Research Series Supervision, 64, 1-25.

Ritter, J. R. (2003). Behavioral finance. Pacific-Basin Finance Journal, 11(4), 429-437.

Saracel, N., \& Aksoy, I. (2020). Toplum 5.0: Süper ak1llı toplum. Social Sciences Research Journal, 9(2), 26-34.

Şendoğdu, A. A. (2020). Endüstri 4.0 devriminde robotik kaynaklar yönetimi bağlamında insan kaynakları yönetiminde yeni açılımların kaçınılmazlığı. Atatürk Üniversitesi İktisadi ve İdari Bilimler Dergisi, 34(1), 141-161.

Taner, B., \& Akkaya, G. C. (2016). Sermaye piyasası faaliyet alanı ve menkul kıymetler (3. baskı). Detay Yayıncilik.

Yıldız, M., \& Yıldırım B. F. (2018). Yapay zekâ ve robotik sistemlerin kütüphanecilik mesleğine olan etkileri. Türk Kütüphaneciliği, 32(1), 26-32. 


\section{Introduction}

\section{EXTENDED ABSTRACT}

The rapid increase in interaction among countries and technological developments with the globalizing world also affects societies. There are various important stages in the development of societies. The Society 5.0 we live in today is the latest extension of these developments. Society 5.0, as an extension of Industry 4.0, was introduced in 2017 by the Japanese Prime Minister Shinzo Abe's phrase "Super Intelligent Society". Abe explained the purpose of Society 5.0 as raising the quality of life of society as an innovative society owing to technological developments. With the technological developments, the use of robotic resources is increasing day by day. Benefiting from robotic resources, which will replace human resources, be faster, error-free, have no problems with being human, and have 24/7 working capacity, becomes a more preferred option in terms of economy. Although the prediction of Society 5.0 that technological developments will increase the welfare of the society sounds good, we have to consider it as a phenomenon that should be handled with all its aspects with a holistic approach. Even though technological developments are handled in every period in terms of facilitating human life, the dramatic developments and the use of robotic resources may create some problems in the future. Although there are great benefits from using robotic resources from a short-term perspective, it is necessary to examine possible situations if there is no limit to benefiting from robotic resources in the long-term. It is a well-known fact that in the fierce competitive environment of the capitalist world, Profit comes first. Robotic resource management in terms of replacing human resources should be examined in detail with this aspect.

Benefiting from robotic resources has relatively many advantages over human resources. Robots don't do many of the things that being human requires. For example, They don't demand salary, bonus, overtime, permission, advance, retirement etc. In addition to their abilities to work faster and error-free than human resources, They don't have some human-specific requests and complaints. Considering their advantages, it is an understandable situation that employers prefer to be substituted for human resources. On the other hand, human needs are endless, so human resources have a consumer side as opposed to being a producer. they have too many demands as purchasing/renewing house, furniture, car etc., eating, drinking, travelling, entertainment, personal care and many other demands are limitless. they must have income to do all this.

As a foresight of Society 5.0 and as a result of technological developments, Leveraging robotic resources will become more and more common. Utilizing robotic resources will have a supply-increasing effect when considered in terms of the supply side of the economy. However, when robotic resource management is unlimited, a significant part of human resources may lose their jobs. In this case, it is clear that there will be a demand shrinking if most of the human resources, which are the subject of the demand part of the economy, lose their jobs. The deterioration of the demand and supply gap of the economy in the form of excess supply and insufficient demand may result in the loss of more people's jobs. It is not possible to have an idea about how this situation will go on like this. Then, it is clear that there should be a limit in utilizing robotic resources as a substitute for human resources, and the issue to be discussed is what the limit should be and how it should be implemented.

Today, robots need to be managed, Since it is seen as a resource just like human, with the aspect that substitutes human in business life. "Robotic Resource Management" (RRM) was first put forward as a concept by Şendoğdu (Şendoğdu, 2020). Human Resource Management is now evolving towards human and robot collaboration, including Robotic Resource Management.

\section{Materials and Methods}

Secondary data were used and compilation study was made.

\section{Findings}

In the context of Society 5.0, can we move from an information society to a super-smart society with the collaboration of Robotic Resource Management - Human Resource Management? The answer to this critical question is again at the hands of human, and the success of Robotic Resource Management or losing jobs of many human resources will be the determinants of this. Here, our suggestion to solve the dilemma is that Pareto Optimum should be considered as a tool/measure, and 20/80 ratio of Pareto Optimum should be considered as reference, $20 \%$ robotic resource and $80 \%$ human resource. Otherwise, it is not necessary to be a soothsayer to say that the destructive effects will be enormous, although it is difficult to predict the consequences of the absence of any 
measure and the possibility of the power going out of control.

\section{Discussion}

Taking advantage of the Pareto Optimum for the solution of this dilemma is a contract just like the Kyoto Protocol (United Nations Framework Convention on Climate Change, which covers the regulations on carbon dioxide and greenhouse gas emissions), which will be signed by the consensus of all world leaders, especially the leaders of developed countries, under the leadership of the International Labor Organization (ILO). (Unfortunately, the USA, China and India, which caused the most damage to the world, withdrew from this convention for the benefit of humanity) and the "Pareto Optimum Protocol" (POP) with harsh sanctions in case of non-compliance is recommended. In this context, it is stated that there should be a limit on the collaboration of Human Resources Management and Robotic Resource Management with the "Pareto Optimum Protocol" (POP), and this should be in favor of $80 \%$ human resources, as in 20/80 in the Pareto Optimum, and the use of robotic resources should be limited to $20 \%$ is to draw attention.

What can be done today before it's too late, in order not to be exposed to a situation that can lead to the long-term disaster of the short-term gains of the human ego and that we cannot think of how to compensate for this? Finding an answer to the question and focusing on this vitally important issue, doing mental gymnastics and proposing the "Pareto Optimum Protocol" (POP) constitute the original aspect of the study. 